\title{
Peer review: Not in crisis ... but vibrant in its growing diversity
}

Not in crisis...but vibrant in its growing diversity. ${ }^{1(p .49)}$

In this issue of the South African Journal of Science (SAJS), we commemorate international Peer Review Week (21-25 September 2020). This annual event began informally in September 2015 as a partnership between $\mathrm{ORCID}^{\circledR}$, the Open Researcher and Contributor ID, and the American Association for the Advancement of Science, the publisher of the Science journals. They initiated a powerful international conversation encouraging scholars to reflect regularly on the multiple features of peer review, to re-assess best practice, to debate strengths and weaknesses, and to examine possible enhancements.

With increased support the following year it was decided to have an annual theme which, in 2016, was 'Recognising peer review'. The topic was thus broadened from publications to include other areas of academic peer evaluation, like grant and employment applications and conference abstracts. In 2017, the week was linked to an international congress on 'Transparency in peer review', while 2018 concentrated on 'Diversity in peer review', considering situations beyond the Global North to include racial and gender diversity. Apparently, this topic was only 'Somewhat successful ... [and] ... remains a challenge'. ${ }^{2}$ Last year, when 29 organisations were involved, the theme was 'Quality in peer review'. ${ }^{3}$

The year 2020 has been shattering, with the COVID-19 pandemic throwing societies and economies, along with the lives of researchers and the work of scholarly publishing, into disarray. As we confront fake news, a social media frenzy, scientific uncertainty and a crisis in academe, the chosen theme for 2020 is appropriately 'Trust in peer review'. ${ }^{4}$

The history of peer reviewing in South Africa has been neglected. The SAJS began more than a century ago as the Proceedings of the South African Association for the Advancement of Science and robust discussions after presentations at annual meetings were certainly a form of peer appraisal, but there is no clear evidence of when external peer review before publication became the Journal's convention.

Many academics suppose that external peer reviewing is well entrenched and has existed in its current form for an extremely long time, but this is not so and the analyses of Newman ${ }^{5}$ and Baldwin ${ }^{6}$ are informative in this regard. The process was haphazard and editorial judgement was the norm before peer review established itself in the late 20th century, and it evolved only because science funders (generally governments) wanted assurance from more than the researchers themselves that a funding investment would be scientifically rewarding. Nature began external peer review only in 1973 and the majority of science journals did so during the 1970s and 1980s; peer review accelerated as 'publish or perish' became endemic.

In this issue we present some current concerns around trust and peer review. Wolfgang Preiser and Rika Preiser grapple with the underlying concept of trust, arguing that COVID-19 may be re-shaping how scientific knowledge is verified. Growing numbers of retracted articles suggest many shortfalls in peer review and results communicated in preprints and the media may be, if not actually incorrect, certainly less than thorough. The effect of distrust of the scientific process itself is worrying, but the authors conclude that exhaustive peer review is - more than ever - absolutely vital to defend reliable science.

As Editor of the South African Medical Journal, Bridget Farham is in the vortex of COVID-19 problems relating to preprints and pressure on journals to fast track manuscripts. She provides concrete examples of how peer review is the process that most ensures trust, acknowledging that - whatever its flaws - it remains the gold standard for publishing reliable research results.
Keyan Tomaselli is also concerned by the numerous retractions of premature research that erode trust. In his words: 'This is not necessarily fake science, but potentially good science managed badly.' However, his view is that oversight through South African institutions, such as the Academy of Science of South Africa (ASSAf), the National Research Foundation (NRF) and the Department of Higher Education and Training, ensure high quality by supporting trustworthy peer review.

In his contribution, Robin Crewe, the Chair of ASSAf's Committee on Scholarly Publishing in South Africa, explains how ASSAf assures the quality of South African journals as a whole. Analogous to the peer review undertaken by journals of research manuscripts submitted to them, the external peer review of groups of journals is entirely novel. In this way, trust in the journals themselves is secured by review panels that identify flaws and recommend improvements. These reviews add a further element of trust in the work of South African academics who publish in these journals. ASSAf is also responsible for producing the 'Code of Best Practice in Scholarly Journal Publishing, Editing and Peer Review'7, a further safeguard against malpractice.

ASSAf's role is also highlighted by Johann Tempelhoff who reports on a peer review webinar hosted by the Academy on 31 July 2020 that attracted more than 300 registrants and generated considerable discussion. Chaired by Lucienne Abrahams, the presenters included Salmina Mokgehle, an Associate Editor Mentee of SAJS. Discussion was lively and critical, but as Tempelhoff concludes, the Pandora's box of peer reviewing brings forth more positive than negative results for knowledge inquiry, which is not to say that improvements cannot be made.

Steven Johnson follows up on an earlier publication ${ }^{8}$ in which he scrutinised the role of the NRF in the peer-review process. Given that the NRF's academic rating process engages peer reviewers in assessing researchers' CVs, while the $h$-index is a measure of the productivity and citation impact of the publications of researchers, Johnson investigated whether the two were satisfactorily aligned for researchers in the biological sciences. He concludes that this is the case, lending weight to trusting in good peer review at all levels of scholarship.

Academics and publishers must ensure that trust is not eroded and that the process is equitable and fair to everyone involved in order to produce reliable evidence-based knowledge.

\section{References}

1. Ware M. Peer review: Recent experience and future directions. New Rev Inf Netw. 2011;16(1):23-53. https://doi.org/10.1080/13614576.2011.566812

2. Global state of peer review 2018. Publons/Clarivate Analytics; 2018. https:// doi.org/10.14322/publons.GSPR2018

3. Meadows A. Peer review week is five! The Scholarly Kitchen. 2019 June 26 [cited 2020 Aug 31]. Available from: https://scholarlykitchen.sspnet.org/2019/06/26/peer-review-week-is-five/

4. Meadows A. In peer review week we trust. The Scholarly Kitchen. 2020 April 09 [cited 2020 Aug 31]. Available from: https://scholarlykitchen.sspnet. org/2020/04/09/in-peer-review-week-we-trust/

5. Newman B. Authorising geographical knowledge: The development of peer review in The Journal of the Royal Geographical Society, 1830-c.1880. J Hist Geogr. 2019;64:85-97. https://doi.org/10.1016/j.jhg.2019.03.006

6. Baldwin M. Scientific autonomy, public accountability, and the rise of 'Peer Review' in the Cold War United States. Isis. 2018;109(3):538-558. https:// doi.org/10.1086/700070

7. Code of Best Practice in Scholarly Journal Publishing, Editing and Peer Review [webpage on the Internet]. c2018 [cited 2020 Aug 17]. Available from: https://sites.google.com/view/assaf-nsef-best-practice

8. Lovegrove $B G$, Johnson SD. Assessment of research performance in biology: How well do peer review and bibliometry correlate? Bioscience. 2008;58(2):160-164. https://doi.org/10.1641/B580210

\section{HOW TO CITE:}

Carruthers J. Peer review: Not in crisis ... but vibrant in its growing diversity. S Afr J Sci. 2020;116(9/10), Art. \#8853, 1 page

https://doi.org/10.17159/sajs.2020/8853 